\title{
赤霉素代谢及其调控相关基因的差异表达与小麦株高 杂种优势的关系研究
}

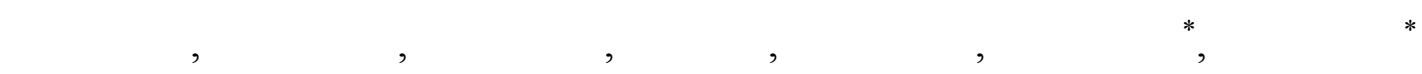

(1) 中国农业大学教育部杂种优势研究与利用重点实验室, 农业生物技术国家重点实验室, 农业部作物基因组与遗传改良重点实验室, 北京市作物遗传改良重点实验室, 北京 100193 ;

(2) 国家植物基因研究中心, 北京 100193

*联系人, E-mail: wheat3392@,cau.edu.cn, qxsun@cau.edu.cn

国家重点基础研究发展计划(编号: 2007CB109000)和国家自然科学基金(批准号: 30671297, 30600392, 30871529, 30971577)资助项目

摘要 植物杂交 $F_{1}$ 的株高一般都表现出明显的杂种优势, 但其形成的分子机理迄今尚未阐述清楚. 本研究以按照 $\mathrm{NC} \|$ 遗传交配设计配制的 16 个杂交组合为材料, 在田间株高性状杂种优势测定的基 础上, 采用实时定量 PCR 技术检测了赤霉素代谢及其调控相关基因在杂交种与亲本抽穗期穗下第 1 节中的表达情况, 并且与株高杂种优势进行了相关分析. 结果表明, 所有杂交组合的株高和第 1 节 均表现出明显的杂种优势, 但因杂交组合和株高性状不同而存在很大的差异. 分析发现, 第 1 节与 株高的中亲杂种优势之间的相关性达到了显著水平 $(r=0.56, P<0.05)$, 说明该节对小麦株高杂种优 势的形成有重要的贡献. 实时定量 PCR 表达分析结果显示, 赤霉素代谢及调控相关基因的表达优势 因杂交组合不同而存在明显的差异, 但第 1 节杂种优势与 $K S$, GA30x2-1, GA20ox2, GA20ox1D, GA-MYB 和 GIDI- 1 基因的表达优势呈显著或极显著正相关, 而与 GAI 和 GA20x-1 基因的表达优势 呈极显著负相关, 这与我们最近提出的小麦株高杂种优势形成的赤霉素分子调控模型相吻合, 说明 赤霉素代谢及调控相关基因的表达改变与株高杂种优势的形成有重要关系.

关键词

小麦

株高

杂种优势

赤霉素

基因表达
杂种优势是指两个以上遗传基础不同的亲本杂 交产生的杂种后代在生长势、生活力、产量和品质等 方面优于亲本的现象, 已经在农业生产上得到了广 泛应用，但对其形成机理的认识仍然非常有限. 生理 生化分析表明, 杂种一代在酶的组成、激素含量、光 合作用、呼吸强度及同化物的运转与积累等特性上与 亲本显著不同 ${ }^{[1 \sim 6]}$. 最近, 全基因组水平上的表达谱 分析结果显示，杂交种与亲本之间存在明显的基因 表达差异, 并且某些差异表达模式与部分农艺性状 的杂种优势存在显著的相关关系. 进一步研究发现, 差异表达基因涉及到转录和翻译、代谢、能量、信号 传导、细胞结构和胁迫响应等类别 ${ }^{[7]}$. 因此, 从基因
组组成上看, 杂交种的全部基因组来自两个亲本, 并 没有新的基因出现，但其性状并非亲本的简单组合， 这可能与来自亲本的基因在杂种一代的时空表达方 式改变有关 ${ }^{[8 \sim 12]}$.

株高是植物的重要农艺性状之一, 并且许多作 物的杂交 $\mathrm{F}_{1}$ 一般都表现出明显的株高杂种优势. 研 究表明, 该性状的优势主要表现为节间长度上, 而不 是节间数目 ${ }^{[13 ~ 18]}$, 这可能与杂交种节间或茎中的赤 霉素含量增加有关 ${ }^{[19 \sim 23]}$. 最近, 我们研究发现, 由于 小麦杂交种与亲本之间赤霉素代谢和信号转导相关 基因的差异表达，使杂交种中的活性赤霉素含量和 对内源GA信号应答的效率明显高于亲本, 进而促使 
杂交种的茎以更快的速度伸长, 最终形成了株高杂 种优势 $[24,25]$. 据此, 初步提出了小麦株高杂种优势形 成的赤霉素分子调控模型 ${ }^{[24]}$.

本研究以按照 NC II 遗传交配设计配制的 16 个杂 交组合为材料进行了研究, 发现赤霉素代谢及其调 控相关基因的表达与株高性状杂种优势之间存在真 实的相关关系, 其中与第 1 节的偏相关分析结果与我 们提出的小麦株高杂种优势形成的赤霉素分子调控 模型相吻合 ${ }^{[24]}$, 这为进一步探讨小麦株高杂种优势 机理提供了参考依据.

\section{1 材料与方法}

(i ) 实验材料与种植. 实验材料以 3197,3472 , 5027 和 5084 为母本, 分 841 , 普分 3 , 圆 81 和柱 1 为父本, 按照 NCII 遗传交配设计配制杂交组合, 于 2006 年秋按照完全随机区组设计将亲本及杂交 $\mathrm{F}_{1}$ 代 播种于中国农业大学昌平实验站, 设 3 个生物学重复. 每个重复中各基因型种植 5 行, 每行 30 粒, 其中 2 行用于株高性状测量, 其余 3 行用于取样进行基因表 达分析(表 1).

表 1 供试小麦亲本的编号、名称及来源

\begin{tabular}{ccc||ccc}
\hline 编号 & 名称 & 来源 & 编号 & 名称 & 来源 \\
\hline 1 & 3197 & 中国农业大学 & 5 & 分 841 & 山西农业科学院 \\
2 & 3472 & 中国农业大学 & 6 & 普分 3 & 山西农业科学院 \\
3 & 5027 & 中国农业大学 & 7 & 圆 81 & 山西农业科学院 \\
4 & 5084 & 中国农业大学 & 8 & 柱 1 & 山西农业科学院 \\
\hline
\end{tabular}

(ii) 株高性状测定及取材. 为了测定株高杂种 优势, 我们调查了杂交种与亲本的最终株高和 5 个节 间长度. 在各重复中, 每个基因型测量 10 株, 取平均 值后计算中亲杂种优势. 由于所用 4 个母本比父本矮, 并且所有杂交 $F_{1}$ 具有明显的株高杂种优势, 所以在 测定株高性状时将与母本相似的剔除, 以避免假杂 种, 其余的随机取样.

用于表达分析的材料部位及其发育时期与Zhang 等人 ${ }^{[24]}$ 相同, 即在幼穗刚露出旗叶时, 取穗下第 1 节 节间以上 $1.5 \mathrm{~cm}$ 区域的茎片段(此区域包含分生组织 和伸长区). 设置 3 个生物学重复, 每 10 个茎片段混 合作为一个生物学重复. 在取样以前, 我们采用微卫 星分子标记对杂交 $F_{1}$ 进行真假鉴定.

(iii) 总 RNA 提取和逆转录. 用 Trizol试剂盒按 其说明书进行总 RNA 提取, 用 $50 \mu \mathrm{L}$ 灭菌 $\mathrm{H}_{2} \mathrm{O}$ 溶解 RNA 样品, 并稀释为 $1 \mu \mathrm{g} / \mu \mathrm{L}$ 进行逆转录. 逆转录反 应总体积 $20 \mu \mathrm{L}$ (含 $2 \mu \mathrm{g}$ 总 RNA, $1 \mu \mathrm{g}$ 针定引物, $5 \mu \mathrm{L}$
$5 \times$ 反转录缓冲液, $5 \mu \mathrm{L} 10 \mathrm{mmol} / \mathrm{L}$ dNTP 混合物, 200 U MMLV 反转录酶, $0.5 \mu \mathrm{L}$ RNA 酶抑制子). $37^{\circ} \mathrm{C}$ 下逆 转录 $1 \mathrm{~h}$ 后, $95^{\circ} \mathrm{C}$ 变性 $5 \mathrm{~min}$, 取 $2 \mu \mathrm{L}$ 反应液用作 $\mathrm{PCR}$ 扩增模板.

(iv) 苂光实时定量PCR分析. 以 $\beta$-actin为内标, 采用与Zhang等人 ${ }^{[24]}$ 相同的赤霉素代谢及其调控相 关基因特异引物进行苂光实时定量 $\mathrm{PCR}$ 分析. 扩增程 序如下: $94^{\circ} \mathrm{C}, 4 \mathrm{~min} ; 94^{\circ} \mathrm{C}, 30 \mathrm{~s}, 66^{\circ} \mathrm{C} / 58^{\circ} \mathrm{C}, 30 \mathrm{~s}, 72^{\circ} \mathrm{C}$, $30 \mathrm{~s}$, 读板, 共 40 次循环; $72^{\circ} \mathrm{C}, 5 \mathrm{~min}$. 每个样本均做 3 个平行管重复, 结果取平均值. 进行结果分析时, 手工设置苂光域值, 确定在该苂光域值下特定的循 环数 $C_{\mathrm{T}}$ 值, 根据 $C_{\mathrm{T}}$ 值, 计算杂交种与亲本的 $C$ 值, $C=$

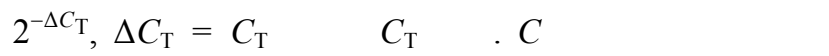
对表达量, 据此计算各基因的中亲表达优势后, 与株 高性状杂种优势进行相关分析.

( v ) 统计分析. 中亲杂种优势 $=\left(\mathrm{F}_{1}\right.$-双亲平 均值)/双亲平均值 $\times 100 \%$. 用 $\mathrm{F}_{1}$ 与双亲中亲值进行 $t$ 测验, 若显著则认为中亲杂种优势显著. 另外, 利用 DPS 3.01 软件进行简单、典型及偏相关分析.

\section{2 结果与分析}

\section{1 小麦株高性状的杂种优势分析}

我们测定了小麦杂交种及其亲本株高和各构成 因素的长度, 并计算了中亲杂种优势. 由表 2 可以看 出, 在所用 16 个小麦杂交组合中, 株高和第 1 节都 表现出明显的杂种优势, 经 $t$ 测验分析均达到显著 或极显著水平，但杂种优势值因杂交组合不同而存 在很大的差异. 例如, 杂交组合 3472/柱 1 的株高杂 种优势为 $21.61 \%$, 但 5084/柱 1 仅为 $4.24 \%$. 分析还 发现, 与株高和第 1 节相比, 穗长、第 2 5 节在不同 杂交组合中的杂种优势值变异更大, 分别为 $3.46 \% \sim 18.63 \% ，-1.81 \% \sim 33.33 \% ，-13.31 \% \sim 44.36 \%$, $-31.65 \% \sim 56.80 \%$ 和 $-27.45 \% \sim 44.13 \%$. 相关分析结 果显示, 仅第 1 节与株高杂种优势之间的相关系数 $(r=0.56)$ 达到显著水平, 说明该节在株高杂种优势 形成过程中起更重要的作用, 所以我们选用其发育 的关键时期, 即抽穗期的穗下第 1 节节间进行了表 达分析.

2.2 赤霉素代谢及其调控相关基因的表达与株高杂 种优势相关分析

我们以小麦抽穗期的穗下第 1 节节间为材料, 利 用Zhang等人 ${ }^{[24]}$ 报道的 14 个赤霉素代谢及其调控相 
关基因引物，采用实时定量PCR方法分析了各基因在 16 个杂种 $\mathrm{F}_{1}$ 及其亲本中的表达情况, 并计算了其中 亲表达优势(表 3). 就同一基因来看, 其在不同杂交 组合中的中亲表达优势存在明显的差异. 例如, GAI 基因在 3197/分 841 组合中的中亲优势值高达 13.07, 但在 3472/普分 3 组合中仅为 -0.89 . 分析还发现, 赤 霉素合成的关键基因 GA20ox2 和GA20ox $1 D$ 在本研究 的 16 个组合中有 12 个表现为负向杂种优势. 在同一 杂交组合中, 不同基因的表达模式也存在很大的差 异. 例如, 在株高杂种优势最为明显的 3472/柱 1 组合 中，赤霉素合成途径中的下游基因 $G A 30 \times 2-1$ 的中亲优
势值高达 7.06, 但是上游基因 $K S$ 为 -0.97 . 以上研究 结果说明, 赤霉素代谢及其调控相关基因在 16 个杂 交组合抽穗期穗下第 1 节节间中的差异表达模式比 较复杂, 没有明显的规律性可寻.

为了确定赤霉素代谢及其调控相关基因的表达与 株高性状优势之间的关系, 我们首先采用典型相关方 法进行了分析. 结果显示, 两组变量之间的典型相关系 数 $\lambda 1$ 和 $\lambda 2$ 达到 0.01 显著水平, $\lambda 3$ 达到 0.05 显著水平, 表明二者存在真实的相关关系(结果未列出). 其次, 为 了找到联系最为密切的变量, 我们进行了偏相关分析, 发现第 1 节杂种优势与 $K S$, GA3ox2-1，GA20ox2,

表 216 个小麦杂交组合株高性状的中亲杂种优势 $(\%)^{\mathrm{a})}$

\begin{tabular}{|c|c|c|c|c|c|c|c|}
\hline 组合 & $\begin{array}{l}\text { 穗长 } \\
\end{array}$ & 第 1 节 & 第 2 节 & 第 3 节 & 第 4 节 & 第 5 节 & 株高 \\
\hline $3197 /$ 分 841 & $5.09 *$ & $9.24 * *$ & $11.48 * *$ & $44.21 * *$ & 0.32 & $-8.23 *$ & $6.13 * *$ \\
\hline 3197/普分 3 & $6.46^{*}$ & $19.25 * *$ & $6.61 *$ & $7.35^{*}$ & $9.19 *$ & 0.66 & $7.99 * *$ \\
\hline 3197/圆 81 & $4.57 *$ & $9.55 * *$ & 0.02 & $-7.32 *$ & -0.28 & 2.16 & $3.23 * *$ \\
\hline 3197/柱 1 & 4.97 & $32.32 * *$ & -1.81 & $-13.31 * *$ & $-31.65 *$ & $-27.45^{*}$ & $9.78 * *$ \\
\hline $3472 /$ 分 841 & $13.20 * *$ & $17.97 * *$ & $19.87 * *$ & 5.72 & -0.79 & -12.17 & $10.63 * *$ \\
\hline 3472/普分 3 & $16.57 * *$ & $31.86 * *$ & $24.36 * *$ & $29.08 * *$ & $20.64 *$ & -6.33 & $15.69 * *$ \\
\hline 3472/圆 81 & $17.25 * *$ & $24.14 * *$ & $17.72 * *$ & $21.95 * *$ & $29.22 *$ & $24.35 *$ & $9.38 * *$ \\
\hline 3472/柱 1 & $18.63 * *$ & $25.66 * *$ & $26.51 * *$ & 43.36 & $56.80 *$ & 44.13 & $21.61 * *$ \\
\hline $5027 /$ 分 841 & $9.29 *$ & $23.90 * *$ & $18.75 * *$ & -1.92 & $-16.81 * *$ & $-25.94 *$ & $8.31 * *$ \\
\hline 5027/普分 3 & $11.10 * *$ & $32.60 * *$ & $23.83 * *$ & $19.42 *$ & $15.61 * *$ & 12.66 & $10.55 * *$ \\
\hline 5027/圆 81 & $11.93 * *$ & $8.35 *$ & $4.23 *$ & 0.70 & -9.65 & $37.04 *$ & $10.91 * *$ \\
\hline 5027/柱 1 & 3.46 & $17.35 * *$ & $11.10 * *$ & $12.80 * *$ & 10.51 & $11.60 *$ & $10.90 * *$ \\
\hline $5084 /$ 分 841 & $10.40 * *$ & $19.69 * *$ & $23.63 * *$ & $16.45 * *$ & $26.84 *$ & -10.62 & $11.92 * *$ \\
\hline 5084/普分 3 & $9.74 *$ & $27.09 * *$ & $33.33 * *$ & $31.78^{*}$ & $27.71 * *$ & $19.45^{*}$ & $11.47 * *$ \\
\hline 5084/圆 81 & 9.39 & $29.00 * *$ & $23.94 * *$ & $25.57 * *$ & $33.41 *$ & $24.73 *$ & $10.70 * *$ \\
\hline 5084/柱 1 & $5.24 *$ & $6.13 *$ & $24.98 * *$ & $14.58 * *$ & $33.96 * *$ & $-21.62 *$ & $4.24 * *$ \\
\hline
\end{tabular}

a) $*$, 差异达到显著水平 $(P<0.05) ; * *$, 差异达到显著水平 $(P<0.01)$

表 316 个小麦杂交组合赤霉素代谢及其调控相关基因的中亲表达优势 a)

\begin{tabular}{|c|c|c|c|c|c|c|c|c|c|c|c|c|c|c|}
\hline 组合 & $G A-M Y B$ & $X E T$ & GAI & $G I P$ & $K S$ & $K A O$ & GID1-1 & GID1-2 & GA2ox-1 & GA3ox2-1 & GA3ox2-2 & GA3ox2-3 & GA20ox2 & GA20ox $1 D$ \\
\hline $3197 /$ 分 841 & 0.30 & 0.17 & 13.07 & 0.23 & -0.61 & 0.01 & -0.53 & -0.51 & -0.24 & 0.68 & 0.40 & 1.27 & -0.61 & -0.30 \\
\hline 3197/普分 3 & -0.73 & 1.09 & 0.29 & 0.44 & -0.51 & -0.74 & 0.24 & 1.67 & -0.59 & 1.65 & 2.25 & -0.14 & -0.72 & 0.79 \\
\hline 3197/圆 81 & 0.76 & 6.71 & 8.76 & 0.06 & -0.89 & -0.82 & -0.26 & -0.18 & 0.20 & 0.49 & 0.78 & 0.27 & -0.80 & 0.09 \\
\hline 3197/柱 1 & 1.04 & -0.36 & -0.60 & 0.43 & -0.88 & -0.79 & -0.52 & -0.56 & -0.17 & 1.91 & -0.66 & -0.39 & -0.08 & -0.27 \\
\hline $3472 /$ 分 841 & -0.23 & -0.86 & -0.32 & 0.12 & -0.33 & -0.61 & -0.51 & -0.20 & -0.44 & 0.62 & -0.37 & 0.06 & -0.98 & -0.70 \\
\hline 3472/普分 3 & 2.16 & 3.28 & -0.89 & -0.50 & -0.75 & -0.86 & -0.10 & 0.32 & -0.21 & 0.33 & -0.11 & -0.02 & -0.98 & -0.74 \\
\hline 3472/圆 81 & 0.93 & 0.05 & 2.61 & -0.14 & -0.90 & -0.78 & 0.21 & -0.17 & -0.18 & -0.62 & 0.34 & 0.17 & -0.87 & -0.59 \\
\hline 3472/柱 1 & -0.73 & -0.98 & -0.92 & 0.81 & -0.97 & -0.27 & 0.68 & 0.48 & 1.29 & 7.26 & 0.07 & -0.45 & -0.20 & -0.65 \\
\hline $5027 /$ 分 841 & 1.23 & -0.16 & -0.75 & 0.18 & 1.11 & 1.24 & -0.49 & 0.03 & 8.11 & 2.84 & 0.81 & 1.43 & -0.67 & -0.32 \\
\hline 5027/普分 3 & 2.49 & -0.53 & 0.17 & -0.49 & 1.47 & -0.57 & -0.30 & 0.13 & 11.11 & 0.01 & -0.03 & 1.26 & 0.02 & 0.24 \\
\hline 5027/圆 81 & 0.55 & -0.57 & 0.70 & 0.19 & -0.90 & -0.91 & -0.04 & 1.01 & 4.02 & 0.27 & -0.05 & -0.03 & 0.52 & -0.12 \\
\hline $5027 /$ 柱 1 & 0.13 & 0.09 & 2.28 & 0.54 & -0.69 & -0.52 & -0.14 & -0.25 & 0.72 & 1.24 & 0.39 & 0.00 & -0.29 & -0.21 \\
\hline $5084 /$ 分 841 & -0.64 & -0.02 & -0.66 & 0.39 & -0.84 & -0.80 & -0.33 & -0.12 & 0.70 & -0.78 & -0.78 & 1.02 & -0.11 & 0.06 \\
\hline 5084/普分 3 & -0.34 & -0.77 & 1.82 & 1.27 & -0.74 & -0.90 & 0.08 & -0.10 & 0.18 & 0.25 & 0.54 & 0.70 & 0.59 & -0.54 \\
\hline 5084/圆 81 & -0.47 & 1.51 & 0.90 & -0.08 & -0.97 & -0.90 & 1.05 & 0.66 & -0.39 & 1.59 & -0.81 & -0.27 & -0.26 & -0.63 \\
\hline 5084/柱 1 & 13.83 & 0.39 & 5.18 & 0.43 & -0.98 & -0.83 & 0.51 & 0.81 & 0.01 & 3.55 & 71.63 & -0.42 & 1.82 & -0.78 \\
\hline
\end{tabular}

a) 中亲表达优势 $=\left(\mathrm{F}_{1}\right.$-双亲平均值 $) /$ 双亲平均值 
GA20ox 1D, GA-MYB 和 GID1-1 基因的表达优势呈显 著或极显著正相关, 而与 $G A I$ 和 GA2ox-1 呈极显著 负相关. 与此相反, 穗长和第 5 节杂种优势与 GA2ox-1 呈显著或极显著正相关, 而与 $K S, K A O$, GA200x2 和 GA200x1D 呈显著负相关. 此外, 第 2 和 4 节杂种优势与 $G A 30 \times 2-3$ 呈显著正相关, 与 $K A O$ 和 GA20ox1D 呈显著负相关(表 4).

\section{3 讨论}

株高性状是小麦重要的育种目标之一, 对于构 建合理株型、增强抗倒伏性及产量形成具有重要意 义. 研究表明, 赤霉素在株高生长发育过程中起着 重要的调控作用。例如, 第一次“绿色革命”的小麦 $R h t$ 基因 ${ }^{[26]}$ 和水稻 $S d 1$ 基因 ${ }^{[27]}$ 分别是赤霉素代谢和信 号转导的关键基因, 但对该激素与株高杂种优势的 关系认识仍然非常有限. 最近, Zhang等人 ${ }^{[24]}$ 以一个 小麦株高强优势组合 (冀矮 8/冀矮 9)为材料, 对赤霉 素代谢及其调控与小麦株高杂种优势表现的关 系 进行了系统分析, 发现控制赤霉素代谢的关键酶基 因的差异表达导致了杂交种中的活性赤霉素含量显 著高于亲本, 同时信号转导基因 $G I D 1$ 和 $G A I$ 使杂交 种对内源 $\mathrm{GA}$ 信号应答的效率比亲本更高, 这导致了 其调控的下游基因(如膨胀素基因、GIP和 $G A-M Y B$ ) 表现为超亲表达, 并最终形成了株高杂种优势 [24,25]. 本研究以 16 个小麦杂交组合为材料, 采用实时定 量PCR技术检测了赤霉素代谢及其调控相关基因在 抽穗期穗下第 1 节节间中的表达优势, 并且与株高杂 种优势进行了偏相关分析, 发现第 1 节
与 $K S, G A 30 \times 2-1, G A 20 o x 2, G A 20 o x 1 D, G A-M Y B$ 和 GID1-1 呈显著或极显著正相关, 与 $G I D 1-2, G A I$, GA2ox-1 和GA3ox2-2 呈显著或极显著负相关, 这与 Zhang等人 ${ }^{[24]}$ 提出的小麦株高杂种优势形成的赤霉 素分子调控模型相吻合, 说明赤霉素代谢及其调控 与株高杂种优势的形成有重要关系.

玉米、大豆和水稻株高性状QTL的动态分析结果 表明, 在不同的发育时期和环境条件下检测到的 QTL存在较大的差异, 说明控制株高的QTLs在不同 发育时期的表达具有选择性和时序性 ${ }^{[28 \sim 30]}$. 本研究 的典型相关分析结果显示, 赤霉素代谢及其调控相 关基因的表达与株高性状的杂种优势之间存在真实 的相关关系，但与第 1 节正相关的基因(如GA2000x2 和GA200x1D)与其他株高性状(如穗长和第 5 节)呈显 著或极显著负相关, 反之亦然, 这说明株高杂种优 势的形成也十分复杂. 据此, 我们认为从基因表达 水平上解析该性状杂种优势形成的分子机理, 需要 首先确定所研究的株高性状及其优势形成的关键发 育时期.

普通小麦为典型的异源六倍体植物, 来自二倍 体祖先的 3 个部分同源基因有的保留了原来的功能, 但许多发生了功能上的分化. 例如, Shitsukawa等人 [31]分析了普通小麦中一个MADS家族基因WLHS1 的 3 个同源基因的基因组结构和功能, 发现 $W L H S 1-A$ 基因存在一个新序列的插入, WLHS1- $B$ 的 DNA高度甲基化, 只有WLHS1-D是有功能的. Nomura等人 ${ }^{[32]}$ 对六倍体小麦中控制次生代谢产物氧氮 杂萗酮合成的 5 个关键代谢基因 (TaBx1 5)的部分

表 4 赤霉素代谢及其调控相关基因的中亲表达优势与株高性状中亲优势的偏相关系数 ${ }^{\text {a) }}$

\begin{tabular}{|c|c|c|c|c|c|c|c|}
\hline 基因 & $\begin{array}{l}\text { 穗长 } \\
\end{array}$ & 第 1 节 & 第 2 节 & 第 3 节 & 第 4 节 & 第 5 节 & 株高 \\
\hline$G A-M Y B$ & 0.07 & $0.98 * *$ & 0 & 0.63 & 0.19 & 0 & 0.49 \\
\hline$X E T$ & -0.90 & -0.55 & -0.23 & -0.79 & -0.58 & $-0.91 *$ & -0.64 \\
\hline$G A I$ & -0.74 & $-0.98 * *$ & -0.85 & 0.60 & -0.47 & $0.96 *$ & -0.75 \\
\hline$G I P$ & 0.83 & 0 & 0.60 & 0.25 & 0.65 & $0.96^{*}$ & 0.25 \\
\hline$K S$ & -0.94 & $0.97 *$ & 0.47 & -0.18 & -0.72 & $-0.95 *$ & -0.64 \\
\hline$K A O$ & -0.96 & -0.38 & $-0.91 *$ & -0.80 & $-0.92 *$ & $-0.95 *$ & -0.81 \\
\hline GID1-1 & 0 & $0.98 * *$ & 0.80 & 0.64 & 0.90 & $0.95 *$ & -0.12 \\
\hline GID1-2 & $0.91 *$ & $-0.91 *$ & 0.55 & 0.63 & 0 & 0.83 & 0.53 \\
\hline GA2ox-1 & $0.93 *$ & $-0.98 * *$ & -0.15 & -0.29 & 0.69 & $0.98 * *$ & 0.32 \\
\hline GA3ox2-1 & 0.81 & $0.92 *$ & 0.76 & 0.81 & 0.78 & -0.59 & 0.86 \\
\hline GA3ox2-2 & -0.16 & $-0.99 * *$ & 0.67 & -0.63 & 0.39 & 0.35 & -0.54 \\
\hline GA3ox2-3 & $0.94 *$ & 0.90 & $0.96 *$ & 0.90 & $0.92 *$ & -0.29 & 0.82 \\
\hline GA20ox 2 & $-0.96 *$ & $0.91 *$ & -0.64 & -0.50 & -0.86 & $-0.95 *$ & -0.53 \\
\hline GA20ox $1 D$ & $-0.96 *$ & $0.91 *$ & $-0.93 *$ & -0.55 & -0.57 & $-0.92 *$ & -0.60 \\
\hline
\end{tabular}

a) *, 差异达到显著水平 $(P<0.05) ; * *$, 差异达到显著水平 $(P<0.01)$ 
同源序列进行了克隆、表达和功能分析，发现来自 B 染色体组的基因对于氧氮杂萗酮合成的贡献最大. 我们研究发现, 3 个部分同源基因的表达与株高杂种 优势之间的偏相关关系有所不同. 例如, 第 1 节与 GA3ox2-1 和 GID1-1 基因之间的偏相关系数分别为 0.92 和 0.98 , 达到显著或极显著水平, 但与 GA3ox2-2 $(r=-0.99)$ 和 GID1-2 $(r=-0.91)$ 呈显著或极显著负
相关，这可能与来自不同基因组的部分同源基因的 功能分化有关, 同时也说明为深入探讨赤霉素代谢 及其调控与小麦株高杂种优势的关系, 需要克隆其 中关键基因的 3 个部分同源序列, 并对其表达进行系 统分析. 当然, 本研究主要是统计学意义上的相关分 析结果, 关于赤霉素代谢及其调控与小麦株高杂种 优势的关系还需要更多的分子生物学证据.

\section{参考文献}

杨太兴, 曾孟潜, 李继耕. 同工酶与玉米杂种优势研究 IV. 关于过氧化物酶同工酶的杂种酶的分析. 遗传, 1981, 3: 31一 33

2 戴景瑞, 罗美中, 韩雅姗. 玉米过氧化物酶和酯酶同工酶与杂种产量的关系。作物学报, 1989, 15: 193-201

3 Li Z Q, Wang Z R. Relationship between heterosis and endogenous plant hormones in liriodendron. Acta Bot Sin, 2002, 44: 698-701

4 Zhao Q Z, Lü D B, Cheng X Y, et al. The heterosis of canopy photosynthetic rate and bleeding intensity of hybrid wheat. Sci Agricult Sin, 2002, 35: 925-928

5 Mohammad A, Sparker Z, Murayama S, et al. Physio-morphological characters of $\mathrm{F}_{1}$ hybrid of rice (Oryza sativa L.) in Japanica-India crosses. Plant Proc Sci, 2001, 4: 196一-201

6 黄铁城, 张爱民. 杂种小麦研究进展. 北京: 农业出版社, 1993. 52-57

7 Zhang Y H, Ni Z F, Yao Y Y, et al. Analysis of genome-wide gene expression in root of wheat hybrid and its parents using Barley1 GeneChip. Prog Nat Sci, 2006, 16: 712-720[DOI]

8 程宁辉, 杨金水, 高燕萍, 等.玉米杂种一代与亲本基因表达差异的初步研究. 科学通报, 1996, 41: 451一 454

9 倪中福，孙其信，吴利民，等。小麦种间与品种间杂交种及其亲本之间基因差异表达比较研究. 农业生物技术学报，2001，9: $366-370$

10 Sun Q X, Wu L M, Ni Z F, et al. Differential gene expression patterns in leaves between hybrids and their parental inbreds are correlated with heterosis in a wheat diallel cross. Plant Sci, 2004, 166: 651-657[DOI]

11 Xiong L Z, Yang G P, Xu C G, et al. Relationships of differential gene expression in leaves with heterosis and heterozygosity in a rice diallel cross. Mol Breed, 1998, 4: 129-136[DOI]

12 吴利民. 小麦杂交种和亲本间基因差异表达模式与杂种优势的关系. 博士学位论文, 北京: 中国农业大学, 2002

13 Davies P J. Plant Hormones: Physiology, Biochemistry and Molecular Biology. Dordrecht, The Netherlands: Kluwer Academic Publishers, 1995

14 Itoh H, Ueguchi-Tanaka M, Kawaide H, et al. The gene encoding tobacco gibberellin $3 \beta$-hydroxylase is expressed at the site of GA action during stem elongation and flower organ development. Plant J, 1999, 20: 15-24[DOI]

15 Yamaguchi S, Smith M W, Brown R G S, et al. Phytochrome regulation and differential expression of gibberellin 3 $\beta$-hydroxylase genes in germinating Arabidopsis seeds. Plant Cell, 1998, 10: 2115-2126

16 Hedden P, Phillips A L. Gibberellin metabolism: new insights revealed by the genes. Trends Plant Sci, 2000, 5: 523-530[DOI]

17 Olszewski N, Sun T, Gubler F. Gibberellins signaling: Biosynthesis, catabolism, and response pathways. Plant Cell, 2002, 14: S61-S80

18 Uozu S, Tanaka-Ueguch M, Kitano H, et al. Characterization of XET-related genes of rice. Plant Physiol, 2000, 122: 853-860[DOI]

19 Rood S B, Blake T J, Paaris R P. Gibberellins and heterosis in maize: II . Response to gibberellic acid and metabolism of [ $\left.{ }^{3} \mathrm{H}\right]$ gibberellin $\mathrm{A}_{20}$. Plant Physiol, 1983, 71: 645-651[DOI]

20 Rood S B, Buzzeli R I, Mander L N, et al. Gibberellins: Aphytohormonal basis for heterosis in maize. Science, 1988, 241: 1216-1218[DOI] Rood S B, Buzzell R I, Major D J, et al. Gibberellins and heterosis in maize quantitative relationships. Crop Sci, 1990, 30: 281-286 Rood S B, Witbeck T J E, Major D J, et al. Gibberellins and heterosis in sorghum. Crop Sci, 1992, 32: 713-718

Bate N J, Rood S B, Blake T J. Gibberellins and heterosis in poplar. Can J Bot, 1987, 66: 1148-1152

Zhang Y, Ni Z F, Yao Y, et al. Gibberellins and heterosis of plant height in wheat (Triticum aestivum L.). BMC Genet, $2007,8: 40$ 张一. 小麦株高杂种优势形成的分子机理研究. 博士学位论文, 北京: 中国农业大学, 2007

Peng J R, Richards D E, Hartley N M, et al. “Green revolution” gene encode mutant gibberellin response modulators. Nature, 1999, 400: $256-261$ [DOI]

27 Monna L N, Kitazawa R, Yoshino J, et al. Positional cloning of rice semi-dwarfing gene, sd-1: Rice "green revolution gene" encodes a mutant enzyme involved in gibberellin synthesis. DNA Res, 2002, 9: 11-17[DOI]

28 严建兵，汤华，黄益勤，等. 不同发育时期玉米株高 QTL 的动态分析. 科学通报, 2003, 48: 1959-1964

29 孙德生, 李文滨, 张忠臣, 等. 大豆株高 QTL 发育动态分析. 作物学报, 2006, 32: 509-514

30 Yan J Q, Zhu J, He C X, et al. Molecular disscetion of developmental behavior of plant height in rice (Oryza sativa L). Genetics, 1998, 150: $1257-1265$

31 Shitsukawa N, Tahira C, Kassai K, et al. Genetic and epigenetic alteration among three homoeologous genes of a class E MADS box gene in hexaploid wheat. Plant Cell, 2007, 19: 1723-1737[DOI]

32 Nomura T A, Ishihara R C, Yanagita T R, et al. Three genomes differentially contribute to the biosynthesis of benzoxazinones in hexaploid wheat. Proc Natl Acad Sci USA, 2005, 102: 16490-16495[DOI] 